\title{
EXPERIMENTAL FORMULA FOR THE WAVE-INDUCED SHIP MOORING FORCE
}

\author{
Meng Xiang-wei ${ }^{1,2}$, Gao Xue-ping ${ }^{1}$,Zhang Wen-zhong ${ }^{3}$,Jiang Yun-peng ${ }^{2}$, \\ The wave force dose not considered at the formula of mooring ship cable force in the Load Code for Harbor \\ Engineering[JTJ215-98]. This brought the inconvenience to the calculation of designed cable force for mooring ship. \\ By means of analysis for the laboratory model test result of mooring ship cable force under wave effect, Wave force \\ formula of mooring ship under wave effect was gained. This formula well reflected the influence of ship size, ship \\ load , ship rolling period, ship pitch period, wave period and wave height. The formula can be used in the calculation \\ of standard value of mooring ship cable force under the wave effection, also it can be used to instruct the wave model \\ test for mooring ship.
}

Keywords: mooring ship cable force; wave force; calculation formula; model test

\section{Introduction}

Mooring ship usually bears joint forces of wind, wave and current. Safety of load and unload operation, even that of the ship and wharf structure itself, would be threatened if the ship motion exceeds certain value. Generally, the ship is fixed to bollard or frusta with mooring cable. And the mooring force is relevant to ship characteristics and the loadings mentioned above.

Numerical model for mooring ship motion was usually used to calculate the mooring force, however, the hydrodynamic parameters, which was necessary for numerical model, need validation and verification of physical model. Thus, mooring force of important projects often resorted to physical model ${ }^{[1-2]}$.

In practical design, calculation of mooring force is often carried out according to formula of Load Code for Harbor Engineering in China. The formula considered load of wind and current as well as mooring line arrangement. However, wave-induced mooring force is out of consideration. Thus, it would not reflect the actual circumstance when the wave loading could not be neglectable.

This paper proposed a method of mooring force calculation related to wave force, ship scale and other factors, based on datas of several model tests. The wave-induced mooring force was divided into longitudinal and transverse directions. Firstly, wave force of ship was calculated from mooring force according to the formula of the Code. And then influence of wave height and ship scale on wave force was analyzed. Finally, the formula of wave force was obtained.

Comparative calculation and analysis are also carried out based on data of several model tests. It is concluded that the calculation result fits well with the model test result, while the value of integrated parameter is not changeless. The experiential formula is capable to reflect the influence of ship scale, loading level and wave parameter.

\section{Influence factor of wave force}

Combined forces on the mooring ship could be divided into three parts,

$$
F=F_{1}+F_{2}+F_{3}
$$

Here, $F$ is the total force on the ship, $F_{1}$ is wind force, $F_{2}$ is current force, $F_{3}$ is wave force. $F_{1}, F_{2}$ was studied by plenty of research. In this paper, wave force $F_{3}$ was discussed.

The mooring force of cable under wave was induced by the wave force. Mooring force of cable under wave affection had great relationship with characteristic of ship itself, wave, cable and mooring arrangement. The characteristic of ship included ship scale, load degree and motion characteristic. The wave force has the same relations as mooring force do. The wave force here is not static force, it is dynamic force who induce the cable force directly.

In a word, the wave force could be expressed as following,

$$
F_{3}=f(H, T, \theta, W, L, B, D, d, x, m, g, \ldots \ldots)
$$

\footnotetext{
${ }^{1}$ School of Civil Engineering, Tianjin University, Tianjin 300072

${ }^{2}$ Tianjin Research Institute for Water Transport Engineering, Tianjin 300456

${ }^{3}$ Tianjin Research Institute for Harbor Engineering, Tianjin 300222
} 
Here, $H$ is wave height, $T$ is wave period, $\theta$ is wave direction, $W$ is ship discharge, $L$ is ship length, $B$ is ship width, $D$ is ship draft, $d$ is water depth, $x$ is mooring arrangement, $m$ is additional mass, $g$ is gravity acceleration.

According to analysis of plenty of research results, relationship between wave force or mooring force and the influential factors was obtained as following:

(1) Wave height

When wave height was larger, mooring force or wave force would be larger. It was indicated by analysis of experimental results that the relationship between wave force and wave height was close to linear.

(2) Wave direction

Mooring force with following or inclined sea was much less than that with beam sea. Thus, Beam sea is adverse direction for wave direction.

(3) Ship tonnage

It was demonstrated from the experiment that the relationship between mooring force and ship tonnage was close to linear.

(4) Load degree

It was found from the experiment that the influence of load degree was relatively larger. For the same ship, when the load degree was smaller, ship motion and mooring force would get larger. And different load degree would also affect the discharge and motion characteristic.

(5) Wave period

It was indicated by the experiment that rolling angle would get larger when the wave period was close to inherent rolling period of the ship. Thus, the formula should take the resonance between wave and ship into consideration.

(6) Water depth

It was indicated by many experiments that little difference about mooring force appears with different water depth. Thus, the formula in this paper did not reflect the influence of water depth, which satisfied the requirement of ship mooring.

(7) Water level

Different water level resulted to different angle between the cable and ship. So the influence of water level was replaced of mooring line arrangement.

\section{The wave force formula deducing}

Based on the analysis above, deducing the compute formula of wave force on the ship. The wave force was expressed with two component forces of longitudinal and transverse directions.

\subsection{Transverse wave force}

Wave height, wave direction, wave period, and ship tonnage, ship loading was considered in the formula. Considering the factors $k_{i}(i=1,2,3,4, \cdots)$ and the integrated parameter $x$. The transverse wave force $F_{x}$ expression is:

$$
F_{x}=f\left(x, k_{1}, k_{2}, k_{3}, k_{4}, \cdots \cdots\right)=x k_{1} k_{2} k_{3} k_{4} \cdots \cdots
$$

Relationship between single factor and mooring force was obtained according to the influence mentioned above.

The transverse force has a linear relationship with wave height before the ship. The influence of wave height before the ship was expressed as following:

$$
k_{1}=H(1+\sqrt{|\sin \theta|})
$$

Here $H$ is incident wave height (m), $\theta$ is the angle between wave direction and ship longitudinal axis $\left({ }^{\circ}\right)$.

The influence of wave direction was expressed as following:

$$
k_{2}=\sin \theta
$$

The influence of wave period and rolling period and ship loading degree reference the formula of ship rolling angle ${ }^{[5]}$, was expressed as following:

$$
k_{3}=a_{x}
$$


Here, $a_{x}$ was the parameter reflecting relationship between ship rolling period and wave period. $a_{x}=\frac{1}{\sqrt{\left(1-\left(\frac{T_{x}}{T}\right)^{2}\right)^{2}+4\left(\frac{T_{x}}{T}\right)^{2} \mu_{x}{ }^{2}}}$, Here, $T_{x}$ was rolling period and $T$ is wave period, $\mu_{x}$ was non dimensional damp parameter. $\mu_{x}=0.3 \frac{W}{W_{f}}$. Here, $W$ was ship tonnage (t); $W_{f}$ was load displacement (t).

The influence of ship tonnage was expressed by the scale of area exposed to the wave, shown in formula as following.

$$
k_{4} \approx L D
$$

Here, $D$ was ship draft (m) and $L$ was the length of ship (m).

Consolidation formula (3) (7), considering the harmony of dimension, introduce the $\gamma g$. Then the empirical formula of transverse force was obtained as following:

$$
F_{x}=x H(1+\sqrt{|\sin \theta|}) L D a_{x} \gamma g \sin \theta
$$

Here, $x$ was the integrated parameter, $\gamma$ was density of sea water, taken $1025 \mathrm{~kg} / \mathrm{m}^{3} ; g$ was acceleration of gravity, taken $9.81 \mathrm{~m} / \mathrm{s}^{2}$.

\subsection{Longitudinal wave force}

The longitudinal force was similar with transverse force, just a little difference in parameters.

$$
F_{y}=y H(1+\sqrt{|\cos \theta|}) B D a_{y} \gamma g \cos \theta
$$

Here, $F_{y}$ was longitudinal direction wave force $(\mathrm{N}), y$ was the integrated parameter, $B$ was ship width $(\mathrm{m}), a_{y}$ was the parameter reflecting relationship between ship pitching period and wave period. $\quad a_{y}=\frac{1}{\sqrt{\left(1-\left(\frac{T_{y}}{T}\right)^{2}\right)^{2}+4\left(\frac{T_{y}}{T}\right)^{2} \mu_{y}^{2}}}, \mu_{y}$ was non dimensional damp parameter. $\mu_{y}=0.3 \frac{W}{W_{f}}, T_{y}$ was ship pitching period (s).

\section{Determination of integrated parameters}

Total force on the ship was not found in the experimental data collected, but only the max mooring force under wave loading. Thus, total force (wave force) was calculated by formula of mooring force referenced from Loading Code for Harbor Engineering. And then integrated parameter was obtained from empirical formula of wave force on ship.

Based on plenty of examples of experimental data, almost each case would have satisfactory integrated parameter and the discrete degree was small, which indicated that the empirical formula was formally rational.

The difference of integrated parameter reflected the difference of ship type and experimental method. The recommended value of integrated parameters was as following:

$$
x=0.05 ; y=0.05
$$

\section{Calculated method of cable force}

Mooring ship cable force introduced by wave can be calculated as following:

(1) Calculation of wave force

Transverse wave force was calculated by formula (8). And longitudinal force was calculated by formula (9).

(2) Calculation of cable force

Based on the calculation formula of mooring force induced by the wind and current in The loading code of harbor engineering, The mooring ship cable force induced by wave was calculated as following: 
Mooring force $\mathrm{N}$ could be calculated as following:

$$
N=\frac{K}{n}\left[\frac{\sum F_{x}}{\sin \alpha \cos \beta}+\frac{\sum F_{y}}{\cos \alpha \cos \beta}\right]
$$

Here, $N$ was standard value of mooring force. $\sum F_{x}$ was transverse component of wave force, and $\sum F_{y}$ was longitudinal component of wave force. $K$ was asymmetry parameter of force distribution on bollard. And $\mathrm{n}$ is the reacted number of bollards , when $\mathrm{n}$ was 2 , K taken 1.2 and when $\mathrm{n}>3$, $\mathrm{K}$ taken 1.3. $\alpha$ was angle between plane projection of mooring line and wharf line. $\beta$ was angle between mooring line and plane level. The election of $\mathrm{n}$ and $\alpha$ and $\beta$ was referenced by the Load Code for Harbor Engineering(JTJ215-98).

\section{Calculation example}

Here is an example of model test, where the ship is $145000 \mathrm{~m}^{3}$ and $80000 \mathrm{~m}^{3}$ LNG vessel $^{[6]}$. In the wave model test , the cable force was measured under different loading degree. Main ship dimensions of physical test shown as table 1 .

\begin{tabular}{|c|c|c|c|c|}
\hline \multicolumn{5}{|c|}{ Tab1 Main ship dimensions of physical test } \\
\hline Ship tonnage & $\mathrm{L}(\mathrm{m})$ & $\mathrm{B}(\mathrm{m})$ & $\mathrm{H}(\mathrm{m})$ & $\mathrm{T}(\mathrm{m})$ \\
\hline $80000 \mathrm{~m}^{3}$ LNG & 239.0 & 40.0 & 26.8 & 11.0 \\
\hline $145000 \mathrm{~m}^{3}$ LNG & 281.8 & 43.4 & 26.0 & 11.4 \\
\hline
\end{tabular}

The mooring ship cable force in this model was calculated by the wave force formula and the calculated method of cable force in this paper. Mooring force of three loading degree and different wave height and periods was shown in Fig.1-2, in which the left part was result of fully loaded case, the middle part was result of half loaded case, and the right part was result of empty loaded case. And the abscissa is the serial number of test samples. It was indicated by fig.1-2 that calculation of mooring force accorded well with test result. What's important is that the empirical formula reflected the influence of ship dimension, loading degree and wave on mooring force.

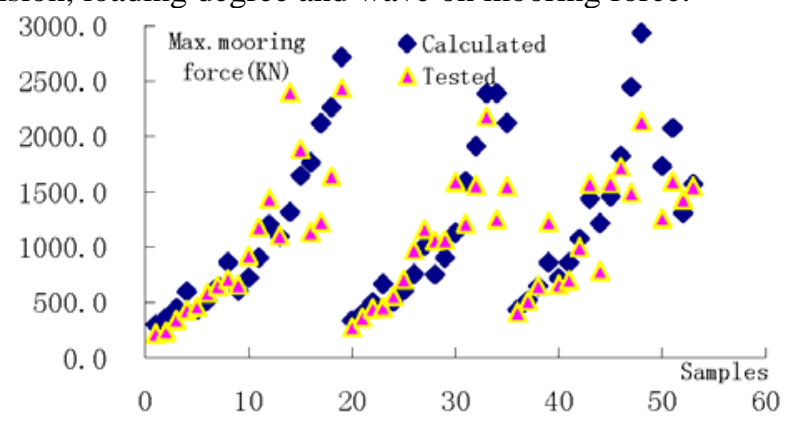

Fig.1 Maximum wave-induced mooring force of $90^{\circ}$ beam wave $(80,000 \mathrm{~m} 3$ LNG ship)

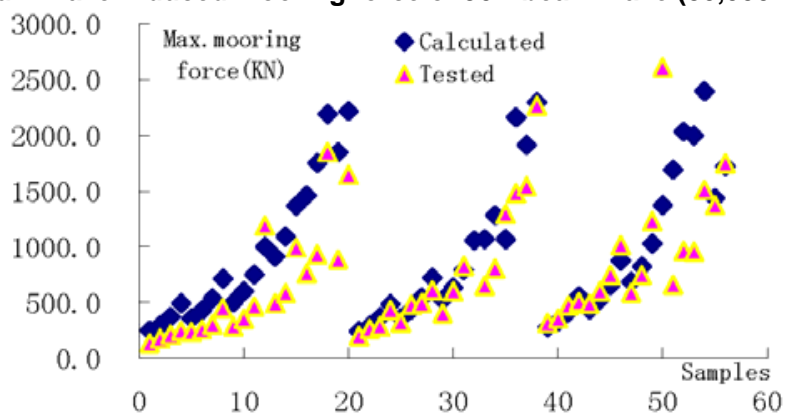

Fig.2 Maximum wave-induced mooring force of $90^{\circ}$ beam wave (145000 m3LNG ship)

\section{Conclusion}

1, Calculated formula of transverse and longitudinal force was obtained by lots of physical model test data. The formula reflect the influence of ship dimension, load degree, wave period, rolling period and pitching period. Results of examples indicated that the empirical formula was formally rational.

2 , The mooring ship motion in the wave is a very complicated case. The wave force dose not considered at the formula of mooring force in the Load Code for Harbor Engineering. The relationship 
between integrated parameter and ship type and mooring arrangement should be seek in further research. And in practical application the integrated parameters could be adjusted by physical model test or prototype observation.

3 , Three dimensional wave force was replaced by transverse and longitudinal component in the formula of this paper. In the future test result of total force and roll pitch damp parameter should be adopted for improvement of the formula.

\section{References}

[1] Zhang Ri-xiang. Liu Zhong-bo. Zhang Ning-chuan. 2003 .An Experimental Study on the Mooring Line Forces \& Impact Forces of a Moored Ship Under the Combined Action of Wind,Wave and Current [J].,China offshore Platform, (01).15-18.

[2] Li Yan. Zheng Bao-you.Gao Feng. Meng Xiang-wei.2007.Model test study on the impact forces and mooring line forces of a moored ship under the combined action of wave and current [J].; The Ocean Engineering, (02).57-63.

[3] Ministry of transport of the People's Republic of China(1998).The Load Code for Harbor Engineering (JTJ215-98). [S].

[4] Jiang Qing. Ge Hong-zheng.Xie Peng.2007.Influence of Ship's Type and Tonnage on the Ship's Mooring Force [J]. Port \& Waterway Engineering, (09).51-59.

[5] Wu Xiuhuan. 1999.Ship and maneuverability and seakeeping [M]. Ministry of transport of the People's Republic of China. p220.

[6] Zhang Wen-zhong. Etc.(2006): Model test of Mooring LNG ship at Jiangsu Provence, Tianjin Port Engineering Institute Ltd. of CCCC. 